\title{
Case Report \\ Rescue of Primary Incomplete Microkeratome Flap with Secondary Femtosecond Laser Flap in LASIK
}

\author{
E. A. Razgulyaeva \\ Tyumen Regional Ophthalmological Treatment Center, Tyumen 625000-625010, Russia \\ Correspondence should be addressed to E. A. Razgulyaeva; dr.razgulyaeva@gmx.info
}

Received 22 April 2014; Revised 14 November 2014; Accepted 14 November 2014; Published 23 November 2014

Academic Editor: Maurizio Battaglia Parodi

Copyright (C) 2014 E. A. Razgulyaeva. This is an open access article distributed under the Creative Commons Attribution License, which permits unrestricted use, distribution, and reproduction in any medium, provided the original work is properly cited.

\begin{abstract}
For laser-assisted in situ keratomileusis (LASIK) retreatments with a previous unsuccessful mechanical microkeratome-assisted surgery, some surgical protocols have been described as feasible, such as relifting of the flap or the creation of a new flap and even the change to a surface ablation procedure (photorefractive keratectomy (PRK)). This case shows the use of femtosecond technology for the creation of a secondary flap to perform LASIK in a cornea with a primary incomplete flap obtained with a mechanical microkeratome. As we were unable to characterize the interface of the first partial lamellar cut, a thick flap was planned and created using a femtosecond laser platform. As the primary cut was very thick in the nasal quadrant, a piece of loose corneal tissue appeared during flap lifting which was fitted in its position and not removed. Despite this condition and considering the regularity of the new femtosecond laser cut, the treatment was uneventful. This case report shows the relevance of a detailed corneal analysis with an advanced imaging technique before performing a secondary flap in a cornea with a primary incomplete flap. The femtosecond laser technology seems to be an excellent tool to manage such cases successfully.
\end{abstract}

\section{Introduction}

Femtosecond laser technology has supposed a great advance for flap creation in LASIK surgery and has demonstrated advantages over conventional mechanical microkeratomes $[1,2]$. The use of mechanical microkeratomes has been shown to be associated with higher rates of epithelial defects [3], displacement of the flap [4], and epithelial ingrowth [5]. Nevertheless, LASIK procedures performed with mechanical microkeratomes have been widely used for years and thus some patients may need a secondary laser treatment as a consequence of an over- or undercorrection, or regression [6]. In such cases refractive surgeons may perform a photorefractive keratectomy (PRK) retreatment, and also a LASIK retreatment with relifting of the original flap or the creation of a new flap in a deeper plane [7]. If flap relifting is not possible, the use of femtosecond technology for the creation of the secondary flap is recommendable due to its high level of predictability with regards to flap depth and geometry. However, a comprehensive preretreatment analysis of the cornea by means of an imaging technique is necessary to avoid a flap cut interfering with the original cut, especially if this cut is irregular or incomplete due to intraoperative complications. This case report shows the relevance of this detailed corneal analysis in a case of a secondary femtolaser flap in a cornea with a primary incomplete microkeratome flap.

\section{Case Report}

A 28-year-old female presented herself at our clinic for refractive laser correction. Her preoperative refraction was -3.75 (sph), -0.75 (cyl) at $176^{\circ}$ in the right eye (RE) and -3.75 (sph), -0.5 (cyl) at $5^{\circ}$ in the left eye (LE). The corrected distance visual acuity (CDVA) was 20/20 and 20/20 in RE and LE, respectively. After a comprehensive ophthalmological examination, LASIK was considered the most adequate surgical option for the treatment of her refractive error. The flap was created using a mechanical microkeratome (Moria M2 Single Use, Moria SA, Antony, France) with a disposable and calibrated Med-Logics minus-20 blade (MedLogics Inc., CA, USA). A flap head of $100 \mu \mathrm{m}$ of thickness was used. Surgery was uneventful in RE but a partial cut 


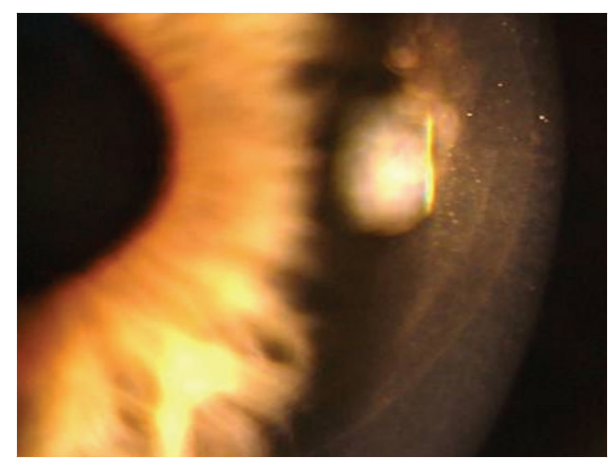

FIGURE 1: Slit-lamp visualization of both flap edges.

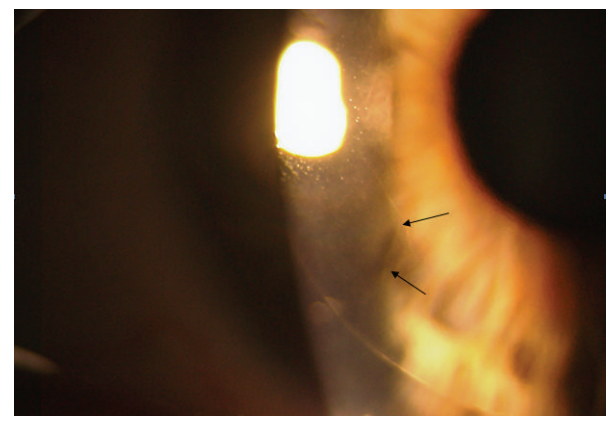

FIGURE 2: Delimitation (black arrows) of the loose corneal tissue that was present in the nasal quadrant and evidenced after lifting the flap.

with the microkeratome was performed in LE due to a loss of suction, and consequently the laser treatment was aborted.

Three months after this episode, when the refraction and the topography were stable, an analysis of the LE cornea was performed with the optical coherence tomography (OCT) system Cirrus HD-OCT (Carl Zeiss Meditec, Germany) in order to determine the position and trajectory of the irregular cut, but the interface of the incomplete primary flap was not visible, even with high magnification. Considering that the primary intended flap had a theoretical central thickness of $100 \mu \mathrm{m}$, a new cut using the IntraLase femtosecond laser FS60 (Abbott Medical Optics, Inc.) was performed using the following settings: diameter of $9 \mathrm{~mm}$ and flap thickness of $140 \mu \mathrm{m}$. This planning was aimed at avoiding an interference with the primary incomplete cut. Although the planning was $140 \mu \mathrm{m}$, according to the OCT image, the flap was approximately of $100-110 \mu \mathrm{m}$ in the center. There was no subepithelial opacity that may have predisposed to an incomplete lamellar pass due to the vertical femtosecond gas breakthrough.

At the immediate postoperative visit, the slit-lamp examination allowed the visualization of both flap edges (Figure 1). Intraoperatively, a piece of loose corneal tissue was observed in the nasal quadrant after lifting the flap which was thought to be the result of the presence of a primary cut of more than $140 \mu \mathrm{m}$ at this position. This piece of corneal tissue was fitted in its position and not removed. Its extension could be also delimited at the slit lamp (Figure 2). In the lower quadrant, the primary microkeratome cut opened up from inside after colliding with the new femtosecond flap,

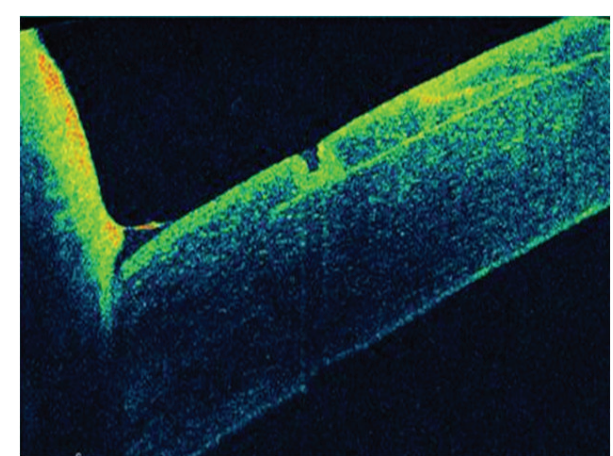

FIGURE 3: In the lower quadrant, the cut done primarily with the microkeratome opened up from inside after colliding with the new femtosecond flap, leading to an epithelial defect that was visualized with the OCT system.

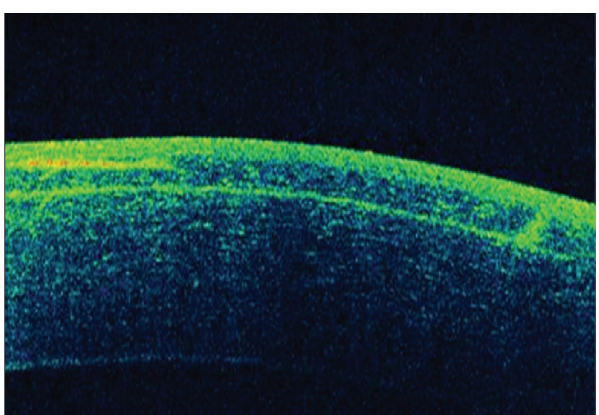

FIGURE 4: OCT image of both flaps in the temporal quadrant showing the abrupt end of the primary cut done with the mechanical microkeratome.

leading to an epithelial defect (Figure 3). In the temporal quadrant, both flaps were clearly positioned at different levels and the abrupt end of the primary mechanical cut was visible in the OCT analysis (Figure 4). Despite this condition and considering the regularity of the new femtosecond cut, laser treatment was uneventfully applied. The day after surgery, the patient achieved an uncorrected distance visual acuity (UDVA) of 0.9 (decimal notation).

\section{Discussion}

As shown in this case report, femtosecond laser-assisted LASIK is a safe option to manage unsuccessful previous LASIK procedures with mechanical microkeratomes. If the primary flap has been uneventfully done and relifting with manual dissection is not possible because of its strong adhesion, the creation of a new vertical side cut with the use of the femtosecond laser creates a net interface that diminishes the mechanical trauma to the epithelium (Güell et al. [8]) and prevents epithelial ingrowth due to the vertical side cut configuration of the femtosecond flap compared to the sloping edge of the mechanical-based flap [9]. Vaddavalli et al. found that femtosecond retreatment using a side cutonly algorithm is effective in the treatment of residual errors after mechanical microkeratome-based LASIK, reducing the 
rates of epithelial ingrowth [10]. The technique from Güell et al. [8] was shown to be also useful if the primary cut is irregular or incomplete, as in our case.

The preoperative assessment of the primary flap through an imaging technique, such as OCT, is essential, especially in the peripheral area, where both primary and secondary flaps are expected to interfere due to the wide variability of thickness of a flap obtained with a mechanical microkeratome [11-13]. Anterior segment OCT (AS-OCT) is an imaging technology that would provide enough information about the characteristics of the primary flap in cases like that presented here [14-16], but in some cases the difficulty in detecting the interface can be significant. This difficulty is especially relevant when a posterior segment OCT is used for the analysis of the cornea because of the unavailability of an AS-OCT at the clinical setting, as happened in our case. This inability of characterizing the interface prior to the second cut can lead to complications such as the presence of some loose tissue, scars, or loss of a sliver of tissue. Pietilä et al. used the FEMTO LDV femtosecond laser (Ziemer Ophthalmic Systems, Port, Switzerland) to perform a new thin flap $(90 \mu \mathrm{m})$ in 81 eyes previously operated with a mechanical microkeratome. They found an improved predictability in flap thickness with their cutting and a low rate of complications such as adhesions related to scars of the primary flap, with no further prevention of the excimer laser ablation treatment. However, these authors did not recommend the creation of a new femtosecond flap in cases of primary free cap or visible scars in the old flap [17]. Garcia-Gonzalez and Teus created a new femtosecond mini-flap, smaller in diameter compared to the previous one, in 10 eyes of 7 patients to avoid the adhesion of the primary flap edges, and without interferences with the peripheral interface, preventing the risk of dislocation of the primary flap [18]. In our case, the lack of an accurate OCT image delimiting the previous partial flap led us to program a new thick femtosecond flap, assuming a higher risk of interference between the primary and secondary flap in the peripheral cornea and consequently to the generation of loose tissue at this area. Fortunately, this complication was easily managed with no further consequences. In conclusion, femtosecond laser-assisted LASIK retreatment in eyes with previous unsuccessful surgery with the creation of an incomplete or irregular flap using a mechanical microkeratome seems to be a safe and highly predictable option. It should be considered that an incomplete microkeratome flap results in an irregular topographic pattern $[19,20]$ that should be treated by means of topography or wavefront-guided procedures in order to minimize the higher order aberrations and corneal irregularity induced with the incomplete cut [2124]. In such cases, it is highly recommended to perform a complete and detailed analysis of the primary flap through AS-OCT imaging technology $[25,26]$ prior to the retreatment in order to define the most appropriate planning for the lamellar cut. Likewise, AS-OCT is able to evaluate epithelial remodeling which can be considered another important biological metric to take into account when evaluating this or any similar complicated refractive surgery cases [25].

\section{Conflict of Interests}

The author has no proprietary or commercial interest in the medical devices that are involved in this paper.

\section{References}

[1] S. Chen, Y. Feng, A. Stojanovic, M. R. Jankov II, and Q. Wang, "Intralase femtosecond laser vs mechanical microkeratomes in LASIK for myopia: a systematic review and meta-analysis," Journal of Refractive Surgery, vol. 28, no. 1, pp. 15-24, 2012.

[2] A. A. Farjo, A. Sugar, S. C. Schallhorn et al., "Femtosecond lasers for LASIK flap creation: a report by the American academy of ophthalmology," Ophthalmology, vol. 120, no. 3, pp. e5-e20, 2013.

[3] G. M. Kezirian and K. G. Stonecipher, "Comparison of the IntraLase femtosecond laser and mechanical keratomes for laser in situ keratomileusis," Journal of Cataract and Refractive Surgery, vol. 30, no. 4, pp. 804-811, 2004.

[4] G. Clare, T. C. B. Moore, C. Grills, A. Leccisotti, J. E. Moore, and S. Schallhorn, "Early flap displacement after LASIK," Ophthalmology, vol. 118, no. 9, pp. 1760-1765, 2011.

[5] E. Letko, M. O. Price, and F. W. Price Jr., "Influence of original flap creation method on incidence of epithelial ingrowth after LASIK retreatment," Journal of Refractive Surgery, vol. 25, no. 11, pp. 1039-1041, 2009.

[6] P. S. Hersh, K. L. Fry, and D. S. Bishop, "Incidence and associations of retreatment after LASIK," Ophthalmology, vol. 110, no. 4, pp. 748-754, 2003.

[7] E. A. Davis, D. R. Hardten, M. Lindstrom, T. W. Samuelson, and R. L. Lindstrom, "LASIK enhancements: a comparison of lifting to recutting the flap," Ophthalmology, vol. 109, no. 12, pp. 2308$2313,2002$.

[8] J. L. Güell, D. Elies, O. Gris, F. Manero, and M. Morral, "Femtosecond laser-assisted enhancements after laser in situ keratomileusis," Journal of Cataract and Refractive Surgery, vol. 37, no. 11, pp. 1928-1931, 2011.

[9] P. K. Vaddavalli and S. H. Yoo, "Femtosecond laser in-situ keratomileusis flap configurations," Current Opinion in Ophthalmology, vol. 22, no. 4, pp. 245-250, 2011.

[10] P. K. Vaddavalli, V. F. Diakonis, A. P. Canto et al., "Complications of femtosecond laser-assisted re-treatment for residual refractive errors after LASIK," Journal of Refractive Surgery, vol. 29, no. 8, pp. 577-580, 2013.

[11] D. Z. Reinstein, H. F. S. Sutton, S. Srivannaboon, R. H. Silverman, T. J. Archer, and D. J. Coleman, "Evaluating microkeratome efficacy by $3 \mathrm{D}$ corneal lamellar flap thickness accuracy and reproducibility using Artemis VHF digital ultrasound arcscanning," Journal of Refractive Surgery, vol. 22, no. 5, pp. 431440, 2006.

[12] J. L. Alió and D. P. Piñero, "Very high-frequency digital ultrasound measurement of the LASIK flap thickness profile using the IntraLase femtosecond laser and M2 and Carriazo-Pendular microkeratomes," Journal of Refractive Surgery, vol. 24, no. 1, pp. 12-23, 2008.

[13] Y. Zhang, Y.-G. Chen, and Y.-J. Xia, "Comparison of corneal flap morphology using AS-OCT in LASIK with the waveLight FS200 femtosecond laser versus a mechanical microkeratome," Journal of Refractive Surgery, vol. 29, no. 5, pp. 320-324, 2013.

[14] J. E. Stahl, D. S. Durrie, F. J. Schwendeman, and A. J. Boghossian, "Anterior segment OCT analysis of thin IntraLase femtosecond 
flaps," Journal of Refractive Surgery, vol. 23, no. 6, pp. 555-558, 2007.

[15] A. C. K. Cheng, T. Ho, S. Lau, A. L. Wong, C. Leung, and D. S. C. Lam, "Measurement of LASIK flap thickness with anterior segment optical coherence tomography," Journal of Refractive Surgery, vol. 24, no. 9, pp. 879-884, 2008.

[16] A. B. Cummings, B. K. Cummings, and G. E. Kelly, "Predictability of corneal flap thickness in laser in situ keratomileusis using a $200 \mathrm{kHz}$ femtosecond laser," Journal of Cataract \& Refractive Surgery, vol. 39, no. 3, pp. 378-385, 2013.

[17] J. Pietilä, A. Huhtala, P. Mäkinen, and H. Uusitalo, "Laser in situ keratomileusis enhancements with the Ziemer FEMTO LDV femtosecond laser following previous LASIK treatments," Graefe's Archive for Clinical and Experimental Ophthalmology, vol. 251, no. 2, pp. 597-602, 2013.

[18] M. Garcia-Gonzalez and M. A. Teus, "Creation of a new femtosecond laser-assisted mini-flap to enhance late regression after LASIK," Journal of Refractive Surgery, vol. 29, no. 8, pp. 564-568, 2013.

[19] V. J. Katsanevaki, N. S. Tsiklis, N. I. Astyrakakis, and I. G. Pallikaris, "Intraoperative management of partial flap during LASIK: a small case series report," Ophthalmology, vol. 112, no. 10, pp. 1710.el-1710.e5, 2005.

[20] I. G. Pallikaris, V. J. Katsanevaki, and S. I. Panagopoulou, "Laser in situ keratomileusis intraoperative complications using one type of microkeratome," Ophthalmology, vol. 109, no. 1, pp. 5763, 2002.

[21] X. Chen, A. Stojanovic, W. Zhou, T. P. Utheim, F. Stojanovic, and Q. Wang, "Transepithelial, topography-guided ablation in the treatment of visual disturbances in LASIK flap or interface complications," Journal of Refractive Surgery, vol. 28, no. 2, pp. 120-126, 2012.

[22] J. L. Alió, D. P. Piñero, and A. B. Plaza Puche, "Corneal wavefront-guided photorefractive keratectomy in patients with irregular corneas after corneal refractive surgery," Journal of Cataract and Refractive Surgery, vol. 34, no. 10, pp. 1727-1735, 2008.

[23] J. L. Alió, D. P. Piñero, and A. B. Plaza Puche, "Corneal wavefront-guided enhancement for high levels of corneal coma aberration after laser in situ keratomileusis," Journal of Cataract and Refractive Surgery, vol. 34, no. 2, pp. 222-231, 2008.

[24] M. R. Jankov II, S. I. Panagopoulou, N. S. Tsiklis, G. C. Hajitanasis, I. M. Aslanides, and I. G. Pallikaris, “Topographyguided treatment of irregular astigmatism with the wavelight excimer laser," Journal of Refractive Surgery, vol. 22, no. 4, pp. 335-344, 2006.

[25] K. Maia Rocha and R. R. Krueger, "Spectral-domain optical coherence tomography epithelial and flap thickness mapping in femtosecond laser-assisted in situ keratomileusis," American Journal of Ophthalmology, vol. 158, pp. 293.e1-301.e1, 2014.

[26] J. Zhang, Y. H. Zhou, L. Tian, and C. B. Zhai, "Comparison of Ziemer FEMTO LDV "Classic" and "Crystal Line" femtosecond laser flap quality by Fourier-domain optical coherence tomography," International Journal of Ophthalmology, vol. 6, no. 5, pp. 611-617, 2013. 


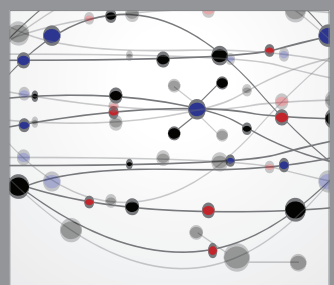

The Scientific World Journal
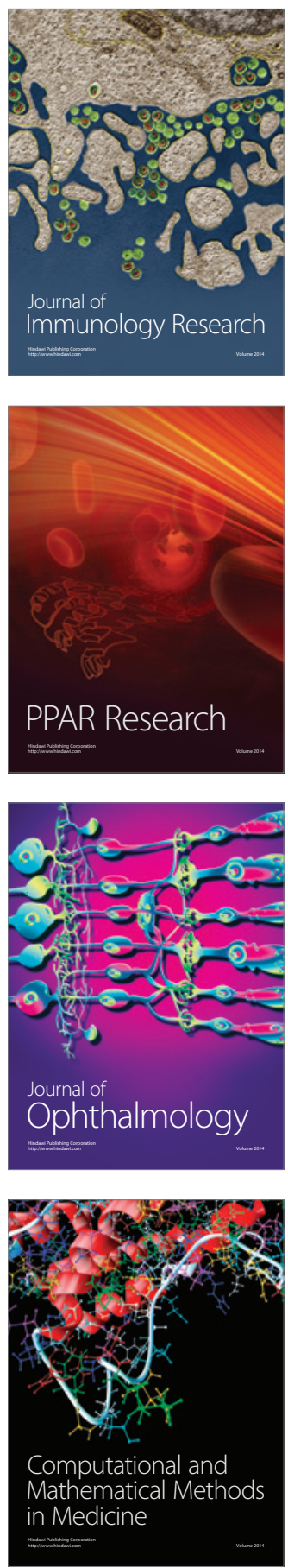

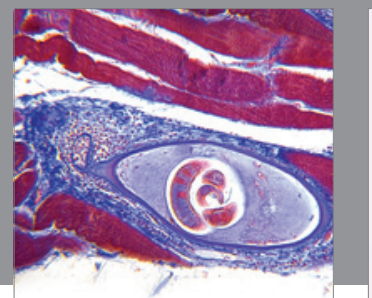

Gastroenterology

Research and Practice
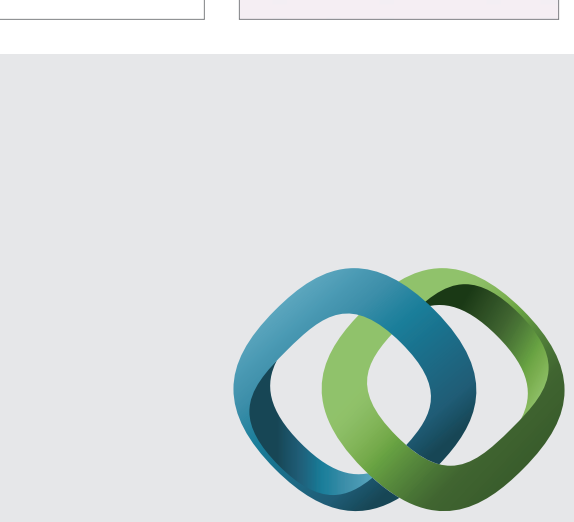

\section{Hindawi}

Submit your manuscripts at

http://www.hindawi.com
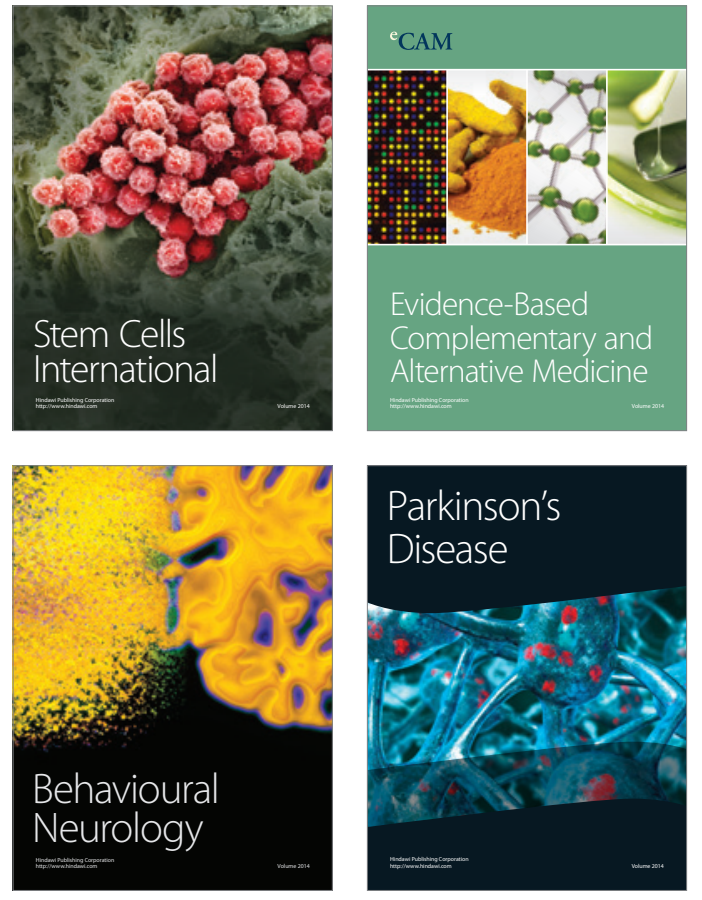
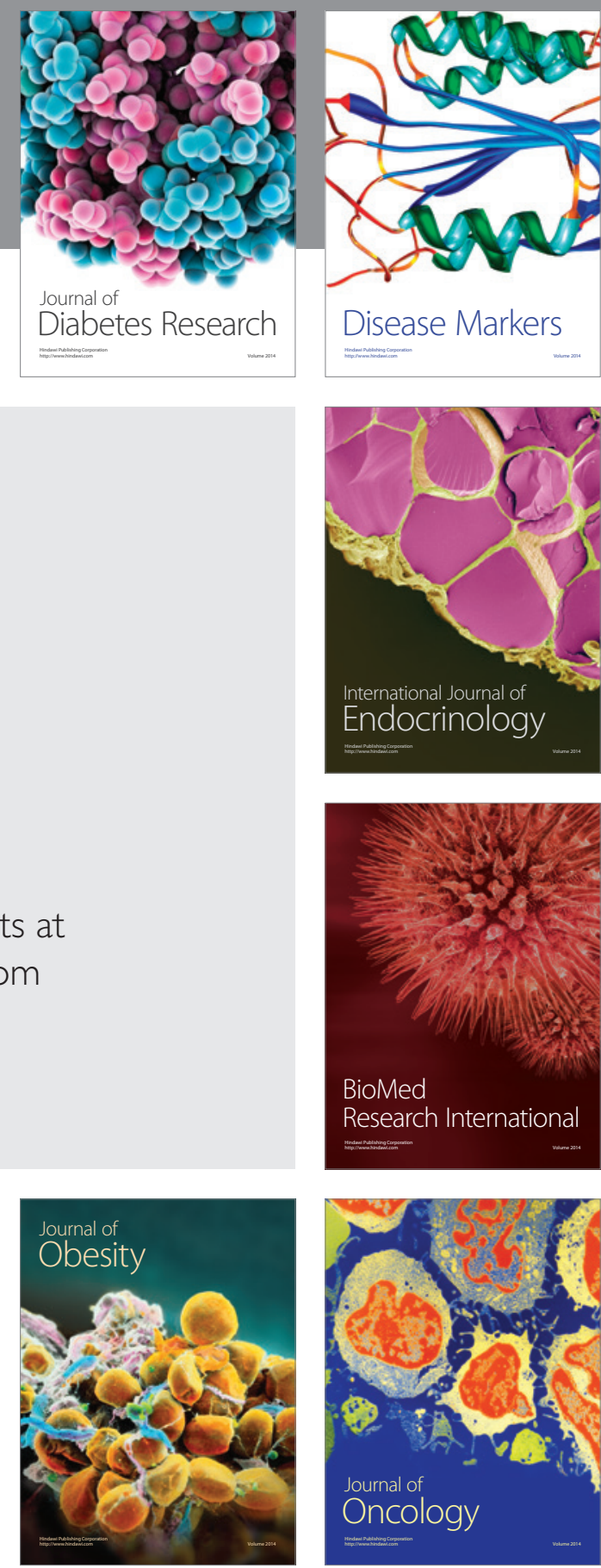

Disease Markers
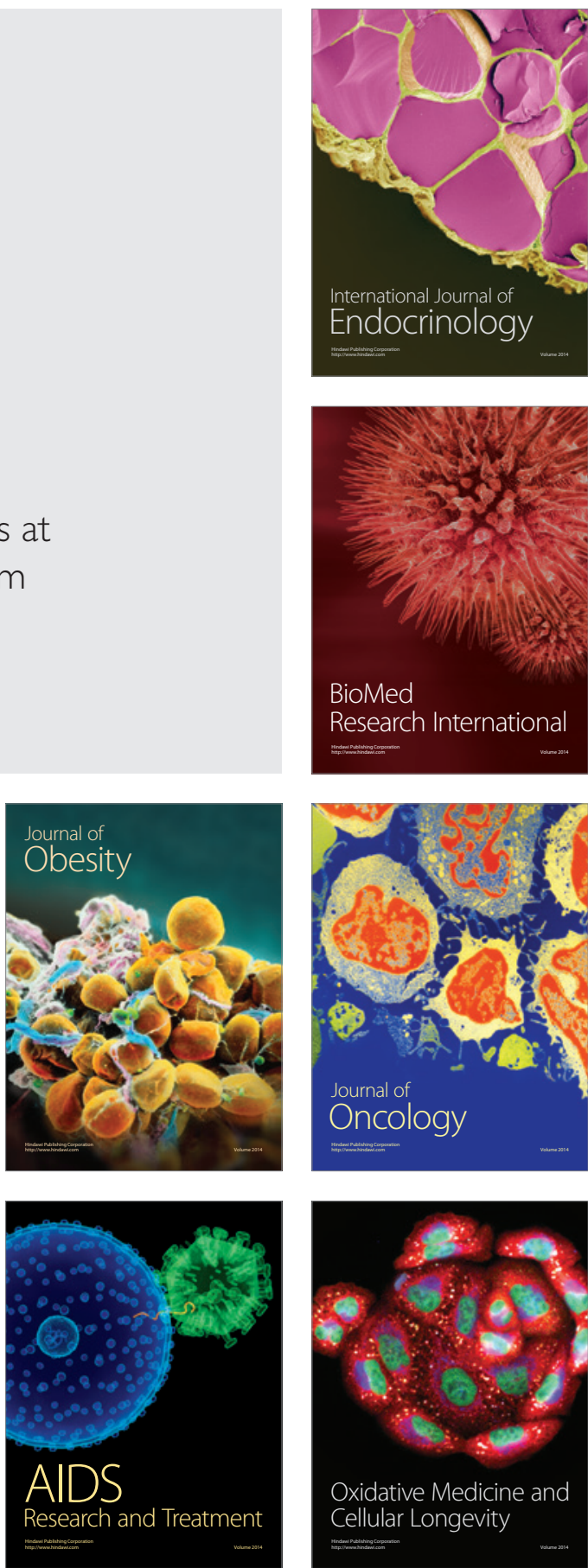